\title{
Nitrous 0 xide - a Viable and Modern Alternative for Inhalation Analgesia in Labor
}

\author{
IOAN SORIN TUDORACHE ${ }^{1}$, OANA DANIELA TOADER ${ }^{2 *}$, ELIANA PETRESCU³, ELENA RUSU1, TUDOR HARSOVESCU1, \\ ANDREI DENNIS VOICHITOIU2 \\ ${ }^{1}$ Titu Maiorescu University, Faculty of Medicine, 67A Gheorghe Petrascu Str., 031593, Bucharest, Romania \\ ${ }^{2}$ Carol Davila University of Medicine and Pharmacy, INSMC Obstetrics and Gynecology Clinical Hospital Polizu, 38-52 Gheorghe \\ Polizu Str., 011062, Bucharest, Romania \\ ${ }^{3}$ Fundeni Clinical Institute, 1 ${ }^{\text {st }}$ Department of Anaesthesia and Critical Care, 258 Bucuresti Rd., 022328, Bucharest, Romania
}

\begin{abstract}
Pain in labor is an important factor in establishing the prognosis of birth and the quality of the conception product, painful uterine contractions being the main physical and psychological stress factor for the pregnant woman that can be decisive for the birth plan. In the management of labor, individualized analgesic therapy is needed to ensure anesthetic comfort as well as cooperation of the pregnant woman in the last part of labor. Analgesia is not supposed to interfere with the mechanisms that are essential during the expulsion, namely with the intensity and duration of the uterine contraction. The last two decades have consecrated natural birth with controlled pain, which allowed the keeping of a limited incidence of caesarean surgery, attitude recommended by the World Health Organization. However, in Romania the trend towards caesarean births has spiked, including due to little promotion of analgesic techniques for natural birth. One of the most used techniques of analgesia, administration of nitrous oxide - $\mathrm{N}_{2} \mathrm{O}$ and oxygen - $\mathrm{O}_{2}$ 50-50\% gaseous mixture represents a viable possibility of pain modulation. Our paper is a descriptive study, examining objective changes of pain perception in a sample of pregnant women with low obstetrical risk, aiming to analyze the quality of analgesia offered by the $\mathrm{N}_{2} \mathrm{O}$ and $\mathrm{O}_{2} 50-50 \%$ gaseous mixture.
\end{abstract}

Keywords: inhaled analgesia, intrapartum pain, nitrous oxide, second part of labor

In the pharmacological management of pain in labor, inhaled analgesia with $\mathrm{N}_{2} \mathrm{O}$ and $\mathrm{O}_{2} 50-50 \%$ is a simple, effective, versatile, and quick acting method for decreasing pain levels without important maternal or fetal risks.

Nitrous oxide is a non-flammable gas with a sweet smell produced by heating ammonium nitrate at $250^{\circ} \mathrm{C}$ : $\mathrm{NH}_{4} \mathrm{NO}_{3} \rightarrow \mathrm{N}_{2} \mathrm{O}+2 \mathrm{H}_{2} \mathrm{O}$. If the temperature is not well controlled in the synthesis process, the resulting gas is contaminated with $\mathrm{NH}_{3}, \mathrm{~N}_{2}, \mathrm{NO}, \mathrm{NO}_{2}$ or $\mathrm{HNO}_{3}$.

At room temperature, the nitrous oxide is a colorless and non-flammable gas, its boiling point being $-88.4^{\circ} \mathrm{C}$ [1]. It can be stored in pressurized vessels, up to $471 \mathrm{psi}$. The weight of the containing cylinder is a relevant indicator for the residual volume of nitrous oxide [2].

The $50-50 \%$ mixture of $\mathrm{N}_{2} \mathrm{O}$ and $\mathrm{O}_{2}$ combines the chemical benefits of both gases. The two gases dissolve into each other and behave differently than they would behave individually. The two gases separate below the critical temperature of $-7^{\circ} \mathrm{C}$, which should be avoided. Another undesirable process is related to the fact that oxygen is more soluble and tends to evaporate faster than nitrous oxide, so that after exhausting a part of the gas mixture, the $N_{2} O$ concentration will increase, with unwanted hypoxic effects. To avoid this, the mixture is kepthomogenized by shaking periodically the gas cylinders [1].

As pharmacokinetic properties, the onset and duration of action are determined by the blood solubility coefficient (blood-gas partition coefficient is 0.47 for $\mathrm{N}_{2} \mathrm{O}$, meaning that it has low solubility in the blood), which causes rapid onset and short duration of action after the administration was interrupted. Minimal alveolar concentration (MAC) is a pharmacodynamics parameter indicating clinical potency of the drug and depends on how much liposoluble is the substance. Having a MAC of 104 [3], the $\mathrm{N}_{2} \mathrm{O}$ and $\mathrm{O}_{2}$ mixture is one of the less potent anesthetic gases, but this is useful, because concentrations under anesthetics levels produce analgesia and anxiolytic effects without affecting the patient's level of consciousness. The mechanism of action in nociceptive signaling is reduction of pain transmission in the central nervous system due to release of endogenous opioids (endorphins) and activation of the descending pain modulation pathway [4-6].

In pregnantwomen, nitrous oxide does not interfere with the release of oxytocin and therefore has no effect on labor duration, amplitude and duration of uterine contraction so does not affect any labor parameters. Generally, $N_{2} O$ has no significant side effects that can endanger the mother's life; the symptoms associated with its administration are limited to nausea, vomiting and headache. These symptoms are rapidly reversible upon discontinuation of nitrous oxide.

Nitrous oxide has no liver metabolism and no urine excretion, the only route of elimination from the body being respiratory. Nitrous oxide passes through the placenta to the fetus but eliminates rapidly as the newborn begins to breathe after expulsion $[6,7]$.

The present study aims to evaluate the therapeutic potential of nitrous oxide in achieving a tolerable pain level in the last phase of labor, knowing that at this stage, the perceived pain is the most intense and the freedom to apply other analgesic methods and techniques is much restricted.

\section{Experimental part}

Material and methods

This is descriptive study conducted between August 2017 and July 2018 on a sample of 84 pregnant women, evaluating the analgesia efficacy of $50-50 \%$ nitrous oxide oxygen gas mixture administered during the last part of 
labor together with epidemiological association between the type and duration of administration and the quality of analgesia, the maternal side effects and the fetal risks.

The inclusion criteria in the study were: pregnancy over 35 weeks, vaginal delivery in the active phase, systematized contractions, dilatation over $6 \mathrm{~cm}$, cranial presentation, agitated parturient with low pain threshold or tolerance and patient's acceptance of receiving the $\mathrm{N}_{2} \mathrm{O}$ and $\mathrm{O}_{2}$ mixture,

Exclusion criteria from the study were: severe respiratory dysfunction, recent ENT interventions, rhinitis, sinusitis, acute respiratory infections, cardiovascular instability, increased risk of vitamin B12 deficiency, psychiatric disorders, inability to support the inhalation mask, gynecological and obstetric antecedents (like posterior non-cranial presentations, fetal pool disproportionation, vaginal discharge), placental pathology (low insertion placenta, premature detachment of a normal insertion placenta), membrane rupture over $6 \mathrm{~h}$ without triggering of uterine contractions, uterine scar tissue, fetal distress or intrauterine growth restriction, fetal malformations and high obstetrical risk (hypertension, diabetes).

The obstetrical diagnosis was recorded, noting the parity, the age of pregnancy, presentation, position or variety of position, membrane status, fetal status, and pelvimetry data. The stage of labor was evaluated by assessing cervical dilation and systemic uterine contraction parameters. The complementary examinations included, along with the usual laboratory tests, the ultrasound scanning of the pregnancy. Birth prognosis and cases hierarchy has been established, including only risk-free parturients seeking the most natural birth possible. All patients were informed and consent was obtained for therapeutic gestures, so the pregnant women were confident, non-psychiatric, and warned of the procedure.

The procedure of administration of the analgesic gas mixture:

The patient must hold tight the inhalation mask. In intermittent administration, the patient breathes in the gas mixture only $30 \mathrm{~s}$ before a contraction starts, because $\mathrm{N}_{2} \mathrm{O}$ takes at least $30 \mathrm{~s}$ to have an analgesic effect. In addition, the maximum potency occurs $50-60 \mathrm{~s}$ after the time of administration, corresponding to the maximum pain sensation triggered by the uterine contraction. Finally, the parturient also expires inside the mask at the end of the contraction, to reduce the amount of $\mathrm{N}_{2} \mathrm{O}$ released in the birth room.

Coherent monitoring strategy of pain markers implied observation of dynamic obstetrical parameters during labor, such as: progress of dilation and presentation, characteristics of painful uterine contractions (rhythmicity, duration, frequency and intensity), membrane status and amniotic fluid characteristics, fetal heart condition (fetal heart beat).

Table 1

EFFECT OF NITROUS OXIDE-OXYGEN MIXTURE ON THE PAIN SCORE DEPENDING ON THE MODE OF ADMINISTRATION

\begin{tabular}{|l|c|c|}
\hline & $\begin{array}{c}\text { Basal line (average } \\
\text { value } \pm \text { SD) }\end{array}$ & $\begin{array}{c}\text { At one hour } \\
\text { (average } \\
\text { value } \pm \text { SD) }\end{array}$ \\
\hline Continuous administration & $8.63 \pm 0.64 \mathrm{SD}$ & $3.61 \pm 0.77 \mathrm{SD}$ \\
\hline Intermittent administration & $8.71 \pm 0.84 \mathrm{SD}$ & $3.71 \pm 0.87 \mathrm{SD}$ \\
\hline
\end{tabular}

We monitored the maternal pain intensity and the analgesia quality by the Visual Analogue Scale (VAS) parameters, developed by the WHO. The advantage of this scale of pain is simplicity, but due to the subjective component of pain and psycho-emotional, educational and cultural fingerprints, pain assessment creates problems of quantification.

The algorithm for pain intensity analysis used the following time lapses:

$\mathrm{T} 1$ = start of gaseous mixture administration and assessment of baseline pain intensity;

$\mathrm{T} 2=\mathrm{T} 1+60 \mathrm{~min}$ and evaluation of pain markers

$\mathrm{T} 3$ = end of gaseous mixture administration and reassessment of pain intensity

As well, we observed cardiovascular maternal parameters (pulse and blood pressure), respiratory (frequency and amplitude of respiratory movements) and general signs, like anxiety and psycho-behavioral changes. We noted the duration of labor and the potential correction of uterine dynamics. Maternal adverse effects (mouth dryness, nausea, vomiting, headache, dizziness, weakness, paresthesia, visual disturbances) and effects on the fetus - fetal heartbeat measuring and the newborn Apgar score at 5 min also were monitored.

\section{Data processing}

The data we use are numbers, mean values \pm standard deviation (SD) or percentage. The statistical analysis was performed using SPSS 20.0. For calculating statistical significance, we use the T-pair test for $p$-index values and the confidence interval. A $p<0.05$ is considered statistically significant.

\section{Results and discussions}

Regarding the parity of the patients included in the study, only $10.71 \%$ were multiparous, the majority ( $89.29 \%$ ) being primiparous. The mean value is $1 \pm 0.31 \mathrm{SD}$. Gestational age (weeks) was $39 \pm 1.32$ SD. The average duration (minutes) of the gaseous mixture administration was 89.88 $\pm 5.48 \mathrm{SD}$.

Regarding the mode of administration of the gaseous mixture (continuous or intermittent), two groups of patients were created: 46 of the parturients $(54.76 \%)$ continuous self-administered the gaseous mixture and 38 (45.23\%) intermittently.

At T1, assessment of the baseline VAS for pain valued between at least 7 points to a maximum of 10 points. At T2, VAS scores ranged between a minimum of 2 points and a maximum 6 points. Eventually, at T3, VAS scores remained between 2 points and 6 points (table 1 ).

Regarding the difference between the initial VAS score and VAS score recorded after one hour of treatment ( $\triangle V A S)$, there was an average change of $5 \pm 1$ points; $p=0.001$, Confidence Interval (Cl) $95 \%(4.72,5.32)$ in the group with continuous administration and by $5 \pm 1$ points; $p=0.001$; $\mathrm{Cl} 95 \%(4.64 ; 5.36)$ in the group with intermittent administration. With respect to the difference between

Table 2

$\mathrm{N}_{2} \mathrm{O}$ EFFECTS ON PAIN SCORE BASED ON DURATION OF

\begin{tabular}{|c|c|c|}
\hline & $\begin{array}{c}\text { Beginning baseline } \\
\text { (average value } \pm \text { SD) }\end{array}$ & $\begin{array}{c}\text { At the end of } \\
\text { administration (average } \\
\text { value } \pm \text { SD) }\end{array}$ \\
\hline $\begin{array}{c}\text { Administration in less } \\
\text { than 90 minutes }\end{array}$ & $8.75 \pm 0.64 \mathrm{SD}$ & $3.68 \pm 0.93 \mathrm{SD}$ \\
\hline $\begin{array}{c}\text { Administration over } \\
90 \text { minutes }\end{array}$ & $8.46 \pm 0.72 \mathrm{SD}$ & $3.58 \pm 0.88 \mathrm{SD}$ \\
\hline
\end{tabular}


initial VAS and post-treatment ( $\triangle \mathrm{VAS})$, the average difference is $5.07 \pm 1.21$ points $(p=0.001, \mathrm{Cl} 95 \%$ (4.48, 5.11)) for the group with administration under $90 \mathrm{~min}$ and with $4.88 \pm 0.95$ points $(p=0.001 ; \mathrm{Cl} 95 \%(4.94 ; 5.56))$ in the group of over $90 \mathrm{~min}$ (table 2).

Completion of birth: $97.61 \%$ were spontaneous births; a forceps application and a caesarean birth were recorded.

The average systolic blood pressure before treatment with the gas mixture was $120.75 \mathrm{mmHg} \pm 8.75$ and diastolic $70.93 \mathrm{mmHg} \pm 8.99$. One hour after the initiation of the procedure, the systolic value recorded an average of $120.04 \mathrm{mmHg} \pm 8.48$ and the diastolic mean value of 70.45 $\mathrm{mmHg} \pm 8.55$. Systolic blood pressure in the group of up to 90 minutes had an average variation of $7.27 \pm 7.36 \mathrm{mmHg}$ $(p=0.001, \mathrm{Cl} 95 \%(-9.17 ;-5.37)$, and the diastolic blood pressure of $0.5 \pm 4.56 \mathrm{mmHg}$ ( $p=0.416, \mathrm{Cl} 95 \%$ (-1.66, 0.70 ). In the over 90 min administration group, systolic blood pressure variation was $9.46 \pm 5.67 \mathrm{mmHg}(p=0.001$, $\mathrm{Cl} 95 \%(-11.85,-7.06))$ and diastolic blood pressure was $2.70 \pm 6.08 \mathrm{mmHg}(\mathrm{p}=0.040, \mathrm{Cl} 95 \%(-0.14 ;-2.18))$. Concerning heart rate, the mean baseline (beats per minute) was $82.93 \pm 6.34$ and one hour after the gaseous mixture administration was $79.64 \pm 5.38$. Heart rate variation has averaged $2.96 \pm 3.80(\mathrm{p}=0.001, \mathrm{Cl} 95 \%$ (1.97, 3.93)).

Nitrous oxide causes a minimal decrease in respiratory volume, but this does not have a real impact on lung function, due to the slightly increased of respiratory rate, so that partial pressure $\mathrm{PCO}$ is maintained at normal levels. In patients without associated pathology, changes in the cardiovascular system are apparently minimal because nitrous oxide has sympathomimetic activity that balances the myocardial decompensation effect that is common in left ventricular dysfunction with preserved ejection fraction $[8,9]$. It is should not be used in patients with severe heart failure, as this would lead to a significant decrease in heart rate, assessed by specific and non-specific biomarkers [10, 11]. Although pelvic thrombophlebitis is a common pathology associated with pregnancy, nitric oxide does not aggravate coagulopathy and does not interfere with usual thrombolytic medication [12].

The average fetal heart rate (beats per min) before administration of the gaseous mixture was $138.4 \pm 4.41$ $\mathrm{SD}$. In the group receiving the gaseous mixture under 90 minutes, fetal heart beats increased by $1.55 \pm 4.60 \mathrm{SD}$ ( $p$ $=0.011, \mathrm{Cl} 95 \%(-2.74,-0.36))$, and in the group receiving over 90 minutes, the fetal heart rate per minute changed with $0.70 \pm 4.46 \mathrm{SD}(p=0.445, \mathrm{Cl} 95 \%(-2.60,1.18))$. The mean weight (g) at birth was $3241 \pm 425.22$ SD. Newborns achieved on average an Apgar score of $8 \pm 0.87$.

In labor, cerebral fetal oxygenation varies during contractions, thus the $50-50 \%$ nitrous oxide-oxygen mixture administration has beneficial effects on fetus by relieving maternal pain and supplementing oxygen for both organisms [13]. Intrauterine growth restriction (IUGR) may be due to a decrease of oxygen delivered to the fetus by the placenta and often requires caesarean extraction to avoid additional hypoxic stress in labor [14]. A proper management of labor by administrating the $50-50 \%$ nitrous oxide-oxygen gaseous mixture ameliorates fetal hypoxia by supplemental oxygen intake and thus allows natural birth in safety in light forms of IUGR [14].

Commonly reported maternal side effects, as nausea, vomiting, headache, dizziness and somnolence, were low in intensity.

In studying the two types of $\mathrm{N}_{2} \mathrm{O}$ and $\mathrm{O}_{2}$ administration, the rate of adverse reactions in the continuous-use group, which recorded thirteen adverse events, was comparative the same to the group intermittent receiving $\mathrm{N}_{2} \mathrm{O}$ and $\mathrm{O}_{2}$ that recorded five adverse events. In terms of duration of administration, the group under $90 \mathrm{~min}$ had five pregnant women with adverse effects. In the group that received the mixture for over $90 \mathrm{~min}$, thirteen adverse events were reported.

The degree of maternal satisfaction was high, with 85\% of the pregnant women being satisfied with the results of the $\mathrm{N}_{2} \mathrm{O}$ and $\mathrm{O}_{2}$ gas mixture, considering that they had a favorable experience.

Unlike other studies [15-20], the present study aimed analyzing the effects of $50-50 \%$ nitrous oxide-oxygen mixture administration only in the last phase of labor, when the severity of the pain is obviously the highest and the possibilities the administration of other drugs and analgesic methods are reduced. The results show that in the present series, which comprises $90 \%$ primiparous, thus with an index of increased pain, nitrous oxide in combination with oxygen $50-50 \%$ reduces statistically significant $(p=0.001)$ pain in labor, the turn in the decrease in pain rapidly, both in intermittent and continuous administration, irrespective of the duration of administration. Thus, summarizing the pain level decreased in the last part of labor by an average of 5 points on the 10-point scale (VAS), from severe pain to moderate pain, in an average duration of administration of the gaseous mixture of about 90 min in both intermittent and continuous administration. The common maternal adverse reactions: nausea, vomiting, headache, dizziness and somnolence were considered minimal by parturients, without affecting their ability to engage in labor. The data processing proves the efficiency of nitrous oxide in solving the equation of intrapartum pain-analgesia.

Factors of confusion and systematic errors are related to pain strong subjective character, being an inter-individual variable. This makes the quantification difficult. The interplay between the type of administration and the duration of administration creates problems in determining the exact degree of involvement of each factor.

\section{Conclusions}

The experience of labor and birth is subjective, complex and influenced by obstetric management of pain. Monitoring of pain through labor must be adapted, folded to the case, and will reduce the sufferings of the new mother and subsequently, in the post-partum, the maternalnewborn psycho-affective relationship will evolve favorably toward an appropriate behavior.

Solving the problem of analgesia - a component of labor management - proves to be as complex as the pain itself, initiated by nociceptive stimuli appearing in the genital system during the parturition. Many methods and analgesic techniques are in use, among which a pertinent pain control key is the administration of $50-50 \%$ nitrous oxide - oxygen gas mixture.

Our study data show that $N_{2} O$ qualifies as a good analgesic that can be recommended to parturients seeking birth as natural as possible. Itpermits controlling pain when the nociceptive level increase in the last phase of labor, resulting in significant pain modulation, regardless of the mode and duration of administration.

It is a healthy technique for mother and fetus, thus responding to modern obstetric goals. The simplicity of administration, the possibility of rapid implementation and disruption, the active involvement of women in pain control, provide this gas mixture with advantages over other techniques and methods of analgesia in labor. Although it is effective and safe, many pregnant women are not 
interested or informed, which emphasizes the need to bring to light the benefits of using $50-50 \%$ nitrous oxide-oxygen mixture for wider use.

\section{References}

1. PECK, T.E., HILL, S.A., Pharmacology for Anesthesia and Intensive care, $4^{\text {st }}$ edition, Cambridge University Press, 2014, p. 110-113.

2. BARASH, P.G., CULLEN, B.F., et all, Clinical Anesthesia, $7^{\text {st }}$ edition, Lippincott, Williams \& Wilkins, Philadelphia, 2013, p. 457-458

3. FULGA, I., CONSTANTINESCU CORCIOVEI, I., COMAN, A.O., CONSTANTINESCU, C.M., ZUGRAVU A., COMAN L. etall, Pharmacology. Ed. Medicalã, Bucharest, 2006, p. 230-245.

4. TULBURE, D., BUBENEK, a ., DROC, G., FILIPESCU, D., FLORESCU, A., GRINPESCU, I., et all, Anesthesia Intensive Therapy Course for Residents and Researchers. University Publishing House Carol Davila, Bucharest, 2006: p. 23-24, 26-47.

5. FUJINAGA, M., MAZE, M., Mol Neurobiol., 25, 2002, p. 167

6. QUOCK, R.M., VAUGHN, L.K., Analgesia, 1, 1995, p. 151

7. ROOKS, J.P., J. Midwif. \&Women's Health. 56, 6, 2011, p. 557

8. COCULESCU, B.I., DINCA, V.G., BALAET, C., MANOLE, G., BALAET, M., STOCHECl, C.M., J. Enzyme Inhib. Med. Chem., 33, 1, 2018, p. 1292

9. COCULESCU, B.I., DINCA, V.G., MANOLE, G., PURCAREA, V.L., STOCHECl, C.M., Rev. Chim. (Bucharest), 69, 10, 2018, p. 2885
10. DINCA, V.G., MANOLE, G., COCHIOR, D., DINCA, A.L., Rev. Chim. (Bucharest), 68, no. 3, 2017, p. 631

11. DINCA, V.G., MANOLE, G., COCHIOR, D., DINCA, A.L., Rev. Chim. (Bucharest), 67, no. 5, 2016, p. 854

12. CAPITANESCU, C., MACOVEI OPRESCU, A. M., IONITA, D., DINCA, G.V., TURCULET, C., MANOLE, G., MACOVEI, R. A., J. Enzyme Inhib. Med. Chem., 31, 6, 2016, p. 1411

13. NASTASE, L., LUMINOS, M., JUGULETE, G., MERISESCU, M.M., STOICESCU S.M., Rev. Chim. (Bucharest), 69, no. 11, 2018, p. 3072

14. NASTASE, L., CRETOIU, D., STOICESCU S.M., Skeletal Muscle Damage in Intrauterine Growth Restriction, in Xiao, J., (eds) Muscle Atrophy, Advances in Experimental Medicine and Biology, 1088, Springer, Singapore, 2018, p. 93-106

15. ROSEN, M.A., Am. J. Obstet. Gynecol., 186, 5, 2002, p. 110

16. SIDEBOTTOM, P., YENTIS, S., Best Pract. and Res. Clin. Anaesthesiol., 15, 3, 2001, p. 447

17. TALEBI, H., NOUROZI, A., J AMILIAN, M., BAHARFAR, N., EGHTESADI-ARAGHI, P., Pak. J. Bio. Sci., 12, 17, 2009, p. 1217

18. PASHA, H., BASIRAT, Z., HAJ AHMADI, M., BAKHTIARI, A., FARAMARZI, M., SALMALIAN, H., Iran Red Cross Med. J ., 14, 12, 2012, p. 792

19. COLLINS, M., STARR, S., BISHOP, J., BAYSINGER, C., Rev. Obstet. Gynecol. 5, 3-4, 2012, p. 126

20. HELLAMS, A., SPRAGUE, T., SALDANHA, C., ARCHAMBAULT, M., J ournal of the American Academy of PAs, 31, 1, 2018, p. 41

$\overline{\text { Manuscript received: } 25.08 .2018}$ 